\title{
N-NITROSOMETHYLETHYLAMINE (NMEA) AND N-NITROSODIETHYLAMINE (NDEA), TWO NEW POTENTIAL DISINFECTION BYPRODUCTS; FORMATION DURING WATER DISINFECTION WITH CHLORINE
}

\section{P. ANDRZEJEWSKI* \\ B. KASPRZYK-HORDERN J. NAWROCKI}

Selected from papers presented in $9^{\text {th }}$ International Conference on Environmental Science and Technology (9CEST2005)

1-3 September 2005, Rhodes island, Greece

\author{
Department of Water Treatment Technology \\ Faculty of Chemistry, Adam Mickiewicz University \\ Drzymały 24, 60-163 Poznań, Poland
}

*to whom all correspondence should be addressed:

Tel: +48 6182934 34; Fax: +48 618293400

e-mail: pandrz@amu.edu.pl

\begin{abstract}
Nitrosamines, mainly $\mathrm{N}$-nitrosodimethylamine (NDMA), $\mathrm{N}$-nitrosomethylethylamine (NMEA) and $\mathrm{N}$-nitrosodiethylamine (NDEA) are highly mutagenic compounds that are suspected of carcinogenic activity to the human body.

The aim of the paper is the evaluation of the possibility of $\mathrm{N}$-nitrosomethylethylamine and $\mathrm{N}$-nitrosodiethylamine formation as a result of the reaction of methylethylamine (MEA) or diethylamine (DEA) respectively with chlorine in the presence of ammonia ions. The optimal conditions of NMEA and NDEA formation were identified as a result of an experiment carried out using different molar ratios of the substrates of reaction.

As the primary aim of the research was the evaluation of the possibility of NMEA and NDEA formation as a result of the reaction of methylethylamine or diethylamine respectively with chlorine in the presence of ammonia ions, a successful result obtained after GC-LRMS analysis was fundamental to the further research. Analytes from postreaction mixtures were concentrated, according to the modified procedure proposed by Mitch et al., by means of liquid/liquid extraction with the usage of methylene chloride. The $\mathrm{N}$-nitrosomethylethylamine and $\mathrm{N}$-nitrosodiethylamine were found in the analyzed extracts of post-reaction mixtures. Apart from NMEA and NDEA identification, the verification of other products with the usage of mass spectra library was also undertaken. The results indicated that the changes in the relative ratio of the substrates influence the concentration of NMEA and NDEA.

The obtained results revealed that NMEA and NDEA are only two of the many products of the reaction taking place in the aqueous solution, which contained methylethylamine or diethylamine and ammonia ions, and was disinfected with chlorine. The other identified products are: ethyl(methyl)formamide and 3-ethyl(methyl)aminopropanenitrile. Therefore $\mathrm{N}$-nitrosomethylethylamine and $\mathrm{N}$-nitrosodiethylamine can be treated as new disinfection by-products similar to THMs, HAAs, MX or NDMA.
\end{abstract}

KEYWORDS: Nitrosamines, water disinfection, chlorination, NMEA, Nnitrosomethylethylamine, NDEA, N-nitrosodimethylamine, disinfection by-products, DBPs 


\section{INTRODUCTION}

The six $\mathrm{N}$-nitrosamines: $\mathrm{N}$ - nitrosodimethylamine (NDMA), $\mathrm{N}$ - nitrosomethylethylamine (NMEA), N- nitrosodiethylamine (NDEA), N- nitrosodi-n-propylamine (NDnPA), Nnitrosodi-n-butylamine (NDnBA) and $\mathrm{N}$ - nitrosodiphenylamine (NDPHA) are of interest to the US EPA due to their probable carcinogenicity [1].

A noticeable feature of this group of nitrosamines is the fact that their carcinogenic properties decrease with an increase of the length of aliphatic chain. $\mathrm{N}$ nitrosodiethylamine, which is characterized by a higher carcinogenicity than $\mathrm{N}$ nitrosodimethylamine, is the single exception. The chemical formulae of the first three $\mathrm{N}$ nitrosamines: NDMA, NMEA and NDEA are given in Fig.1.
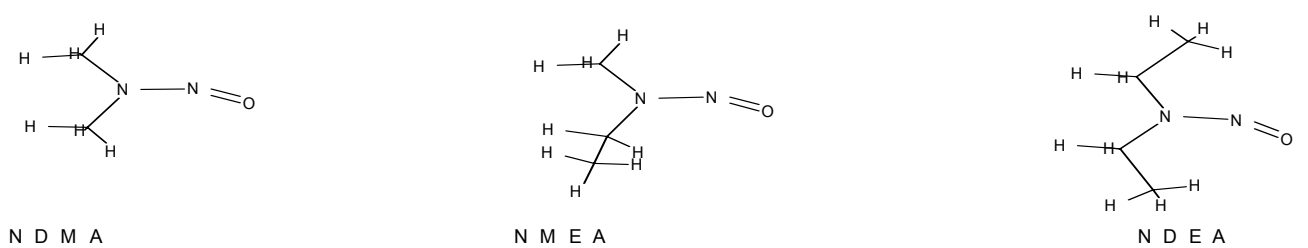

Figure 1. The chemical formulae of the NDMA (N-nitrosodimethylamine), NMEA (Nnitrosomethylethylamine) and NDEA (N-nitrosodiethylamine)

The mechanism of $\mathrm{N}$-nitrosodimethylamine formation was originally connected with the reaction of secondary amines with nitrite, in which $\mathrm{NO}^{+}$played a particular role [2]. Tertiary amines do not react with nitrite. In the case of primary amines the reaction led to the formation of less hazardous compounds and NDMA was the only intermediate product of the reaction. Only the reaction with secondary amines resulted in the formation of the appropriate nitrosamines.

Until NDMA was discovered as a disinfection by-product, nitrosamines were connected only with food products of deteriorating quality. Environmental sources of NDMA include microbial transformation of $\mathrm{N}$-precursors within feedlots and incomplete oxidation of hydrazines [3]. The presence of nitrosamines in water was connected with the presence of nitrite in treated water and wastewater [4].

In 2002 Choi et al. [5] and Mitch et al. [6] reported that N-nitrosodimethylamine is formed during the disinfection of water or sewage containing dimethylamine (DMA) and ammonia with chlorine. Moreover, the concentration of NDMA was closely related to the ratio of chlorine, ammonia ions and dimethylamine. Furthermore, the concentration of NDMA increased with the reaction time and the concentration of monochloramine, which was formed as a result of the interaction of chlorine with ammonia ions and dimethylamine. It should be emphasized that the maximum concentration of NDMA is formed at a pH of 7 8.

The mechanism proposed by Choi et al. [5] and Mitch et al. [6] is based on chlorination leading to the formation of 1,1-dimethylhydrazine, known as unsymmetrical dimethylhydrazine (UDMH). UDMH is formed as a result of the reaction of monochloramine with dimethylamine [5,6]. Furthermore, 1,1-dimethylhydrazine undergoes oxidation to yield many different by-products, including NDMA. The chlorination loss connected to NDMA formation comprises less than $12 \%$ of total chlorination loss after 1 week [4]. The productivity of reaction is the highest at $\mathrm{pH} 6-8$, at which disinfection of water is carried out $[5,6]$.

The authors of this paper made an attempt to assess the influence of chlorine dioxide on the formation of $\mathrm{N}$-nitrosodimethylamine [7]. The authors replaced chlorine (sodium hypochlorite) used by Mitch et al. [6] and Choi et al. [5] with an equivalent dose of 
chlorine dioxide. The results showed a high probability of NDMA formation as a result of chlorine dioxide reaction with dimethylamine in the presence of ammonia ions. Although the mechanism of NDMA formation after the reaction of chlorine dioxide with dimethylamine in the presence of ammonia ions is still unknown, the presence of nitrites and nitrates in a post-reaction mixture suggests that NDMA is formed as result of DMA reaction with nitrites [8].

\section{MATERIALS AND METHODS}

\subsection{Materials}

Reagents: Methylethylamine (Fluka), Diethylamine (Fluka), Ammonia chloride (Fluka) p.a., sodium hypochlorite: solution $11.2 \mathrm{mg} / \mathrm{ml}$, bicarbonate buffer, methylene chloride: (Fluka), puriss. absolute (GC), sodium chloride: (Fluka), p.a., high quality pure water (Millipore).

\subsection{Apparatus}

1. Hewlett-Packard 5890 (HEWLETT-PACKARD) gas chromatograph coupled with lowresolution Hewlett-Packard 5971A mass selective detector (MSD). GC HP-1 fused silica capillary column $(25 \mathrm{~m} \times 0.25 \mathrm{~mm}$ i.d. $\times 1,0 \mu \mathrm{m})$ was used.

GC parameters: Injection mode: splitless of $1 \mu$, injector temperature: $170^{\circ} \mathrm{C}$

Carrier gas: helium, pressure $37.7 \mathrm{kPa}$, flow $0.7 \mathrm{ml} \mathrm{min}^{-1}$ and linear velocity $30.8 \mathrm{~cm} \mathrm{sec}^{-1}$ Temperature program: $40^{\circ} \mathrm{C}(4 \mathrm{~min})-15^{\circ} \mathrm{C} \min ^{-1}-280^{\circ} \mathrm{C}(5 \mathrm{~min}$.)

MS parameters: Resulting Voltage $1400.0 \mathrm{~V}$

Mass range: 30 - 400

Solvent delay: $4.00 \mathrm{~min}$

Data processing system: MS Chem Station

2. SRI $8610 \mathrm{C}$ (SRI INSTRUMENTS) gas chromatograph coupled with NPD detector. GC J\&W RTX-VGC fused silica capillary column (30 m x $0.53 \mathrm{~mm}$ i.d. $\times 3,0 \mu \mathrm{m})$ was used.

GC parameters: Injection mode: on-column, carrier gas: helium with pressure $5 \mathrm{psi}$,

Temperature program: $70^{\circ} \mathrm{C}(2 \mathrm{~min})-13^{\circ} \mathrm{C} \mathrm{min}^{-1}-250^{\circ} \mathrm{C}$

Data processing system: PeakSimple (USA)

3. WATERS 2690 HPLC chromatograph coupled with WATERS 2487 UV-VIS detector, equipped with BIO-Rad Aminex HPX-87H (300 mm x $7.8 \mathrm{~mm}$ ) ion exchange column (ion-exclusion mode) was used.

HPLC parameters: sulphuric acid solution at $\mathrm{pH}=1.5$ as mobile phase with flow 0.6 $\mathrm{ml} / \mathrm{min}$ Injection: $30 \mu \mathrm{l}$, wavelength: $230 \mathrm{~nm}$, oven temperature: $35^{\circ} \mathrm{C}$

Data processing system: CSW (Czech Republic)

\subsection{NMEA and NDEA formation}

The aim of the experiment was to verify, based on the process of NDMA formation, whether $\mathrm{N}$-nitrosomethylethylamine (or N-nitrosodiethylamine) are formed as a result of the reaction with chlorine of methylethylamine (or diethylamine) in the presence of ammonia ions. In order to ensure the conditions of water disinfection, ammonium chloride, the source of ammonia ions, and methylethylamine (or diethylamine), were introduced to the aqueous solution. The $\mathrm{pH}$ of the solution was maintained at 7.8 with bicarbonate buffer. The solution was placed in an amber vial, additionally wrapped in aluminum foil so as to prevent the solution from the sunlight. Subsequently, sodium hypochlorite was added to the solution. The total volume of the sample was selected in order to minimize the volume of the headspace. The reaction time was $0.5-48 \mathrm{~h}$. After the specific time, the reaction was stopped with ascorbic acid with the equimolar ratio of ascorbic acid to sodium hypochlorite. The initial molar ratio methylethylamine (or diethylamine), ammonia chloride and sodium hypochlorite was 1:1:2. The optimal conditions of NMEA and NDEA formation were identified as a result of the experiment carried out using different molar ratios of the substrates of reaction. 


\subsection{NMEA and NDEA analysis}

The post-reaction mixture was analyzed directly by means of the HPLC-UV-IE technique and through a liquid-liquid extraction with methylene chloride by means of the GC-NPD and GC-LRMS technique. The primary aim of the research was the evaluation of the possibility of NMEA and NDEA formation as a result of the reaction of methylethylamine (or diethylamine) with chlorine in the presence of ammonia ions. That is the reason why a successful result obtained after GC-LRMS analysis was fundamental to the further research.

The analyte from the post-reaction mixture was concentrated, according to the modified procedure proposed by Mitch et al. [6], which is by means of liquid/liquid extraction with the usage of methylene chloride. Liquid-liquid extraction with methylene chloride applied for the enrichment of analyte did not ensure sufficient enrichment of the analyte. The problem was previously reported by Mitch et al. [6], who found out that the 'traditional' triple extraction results in the percentage of extraction denoting only $21 \% \pm 10 \%$. This difficulty with extraction efficiency changes was corrected by an application of $d_{6}-$ NDMA as an internal standard [6]. A higher percentage efficiency of extraction than that obtained by Mitch et al. [6] is expected due to a favorable octanol/water coefficient which is: $-0,57$ $\left(\log \mathrm{P}_{\mathrm{o} / \mathrm{w}}\right), 0,04\left(\log \mathrm{P}_{\mathrm{o} / \mathrm{w}}\right)$ and 0,48 $\left(\log \mathrm{P}_{\mathrm{o} / \mathrm{w}}\right)$ for NDMA, NMEA and NDEA respectively [9] and also because of the application of salting out. Apart from NMEA and NDEA identification, the identification of other products with the usage of mass spectra library was also undertaken. The results obtained by GC-LRMS were additionally confirmed by GC-NPD technique.

Due to significant deviation in recovery percentage i.e. $21 \% \pm 10 \%$ [6], liquid-liquid extraction with methylene chloride was not applicable for an investigation into the influence of molar ratio of the reagents and the time of reaction on the concentration of NMEA. However, a modified HPLC-UV-IE method initially used for carboxylic acids determination was successfully applied by the authors [7]. The method is a simple and highly sensitive technique allowing for the determination of nitrosamines at the level of a few micrograms per litre, e.g. $10 \mu \mathrm{g}$ of NMEA per $1 \mathrm{~L}$ and $15 \mu \mathrm{g}$ of NDEA per $1 \mathrm{~L}$ with direct injection of post-reaction mixture. Although this method, due to the level of detection, is not applicable for the environmental samples, it may be used for model experiments, which are carried out in the presence of much higher concentrations of reagents. Long retention times (33.02, 41.09 and 55.82 min for NDMA, NMEA and NDEA respectively) are a disadvantage of the method.

\section{RESULTS AND DISCUSSION}

\subsection{N-nitrosomethylethylamine}

\subsubsection{NMEA formation}

Fig. 2 represents a TIC chromatogram and mass spectrum of the peak of a compound with a retention time of $7.88 \mathrm{~min}$, which was identified in an after-reaction solution of chlorine and methylethylamine in the presence of ammonia after 2 hours contact time.

Mass spectrum of a compound with a retention time of $7.88 \mathrm{~min}$ is compatible with mass spectrum of NMEA taken from mass spectra library (see Fig. 3).

The results clearly indicate that NMEA is formed as a result of chlorine reaction with methylethylamine in the presence of ammonia ions. It is suggested that the reaction follows the scheme proposed by Mitch et al. [6] and Choi et al. [5], although the intermediate product is not UDMH but 1,1-methylethylhydrazyne. 


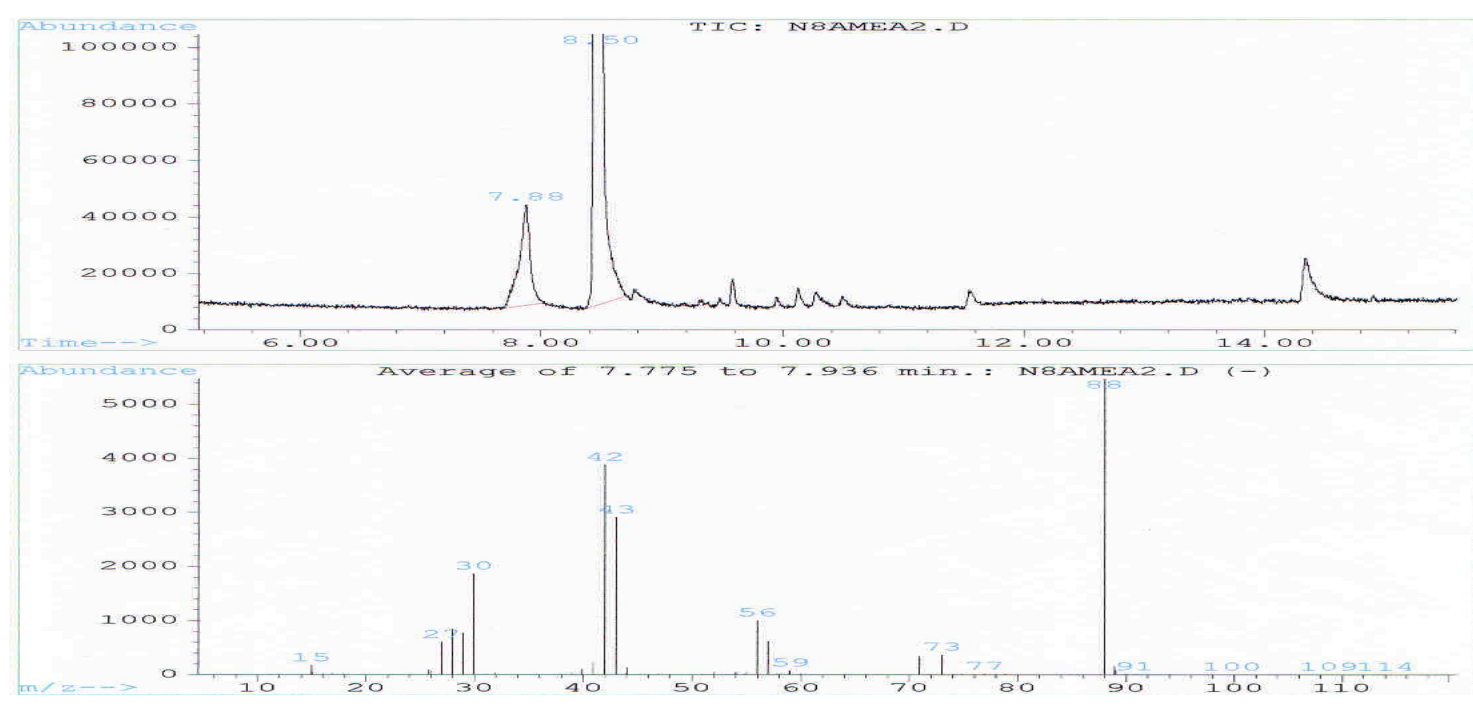

Figure 2. TIC chromatogram and mass spectrum of peak with a retention time of $7.88 \mathrm{~min}$

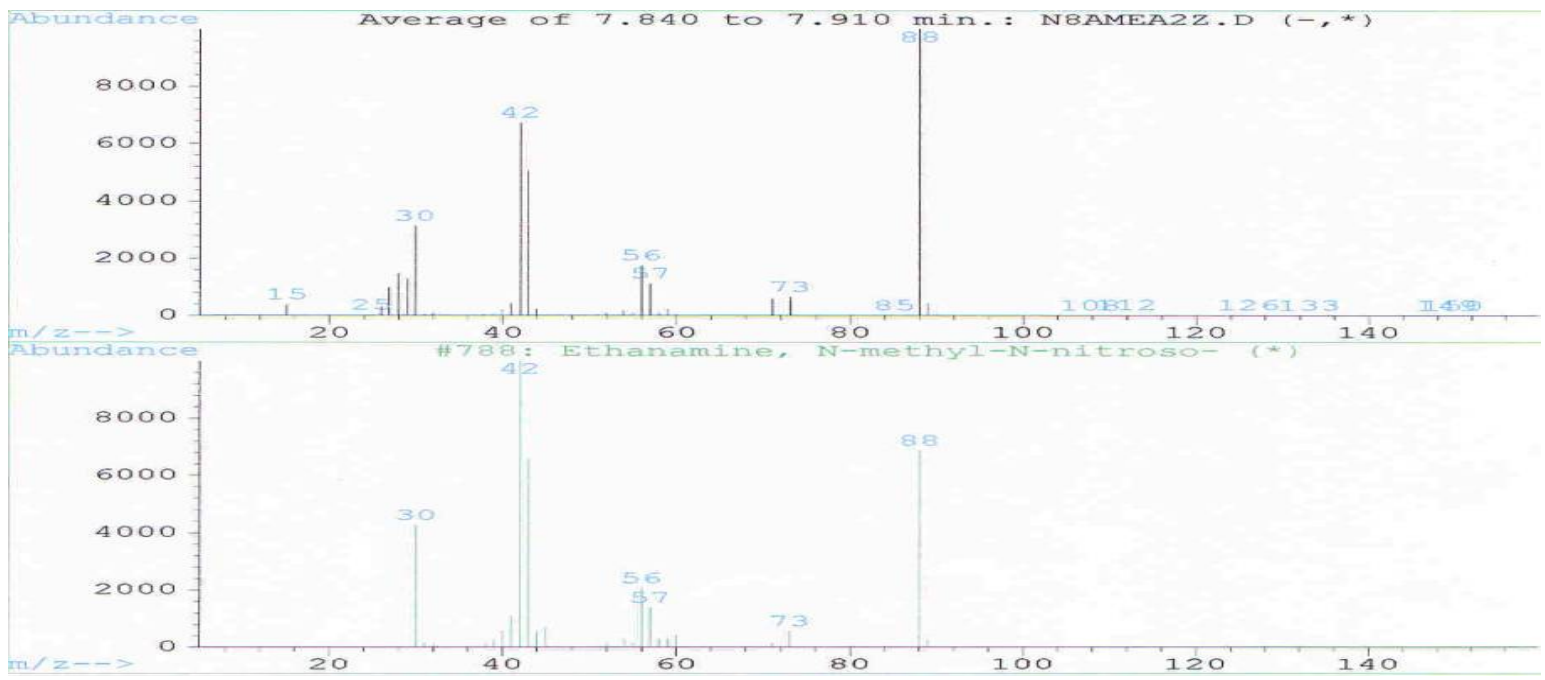

Figure 3. Mass spectrum of a compound with a retention time of $7.88 \mathrm{~min}$ and mass spectrum of NMEA taken from mass spectra library

3.1.2. Influence of relative ratio of substrates on the formation of $\mathrm{N}$ nitrosomethylethylamine

The influence of the concentration of ammonia ions and methylamine on the formation of NMEA was studied. The results are presented in Figure 4 and Figure 5.

The results indicated that the changes in the relative ratio of the substrates influence the concentration of NMEA. An increase of concentration of ammonia ions resulted in an increase of the concentration of NMEA. However, an increase of methylamine concentration under the conditions of constant concentration of chlorine and ammonia resulted primarily in an increase of NMEA concentration up to a maximum level followed by a decrease of its concentration. The above indicates that it is not the concentration of methylethylamine and chlorine that is the essential parameter influencing the potential of NMEA formation but their relative molar ratio.

The maximum MEA/NMEA conversion rate value, calculated as the concentration of MEA to the concentration of NMEA formed quotient, is relatively low and equals $0.14 \%$ [M/M]. However, it means that the presence of MEA in water at a concentration of only $10 \mu \mathrm{g} \mathrm{I}^{-1}$ 
can lead to the formation of $20,9 \mathrm{ng} \mathrm{I}^{-1}$ of NMEA. The maximum admissible concentration of NMEA in water, according USEPA regulations [1] is $20 \mathrm{ng} \mathrm{I}^{-1}$.

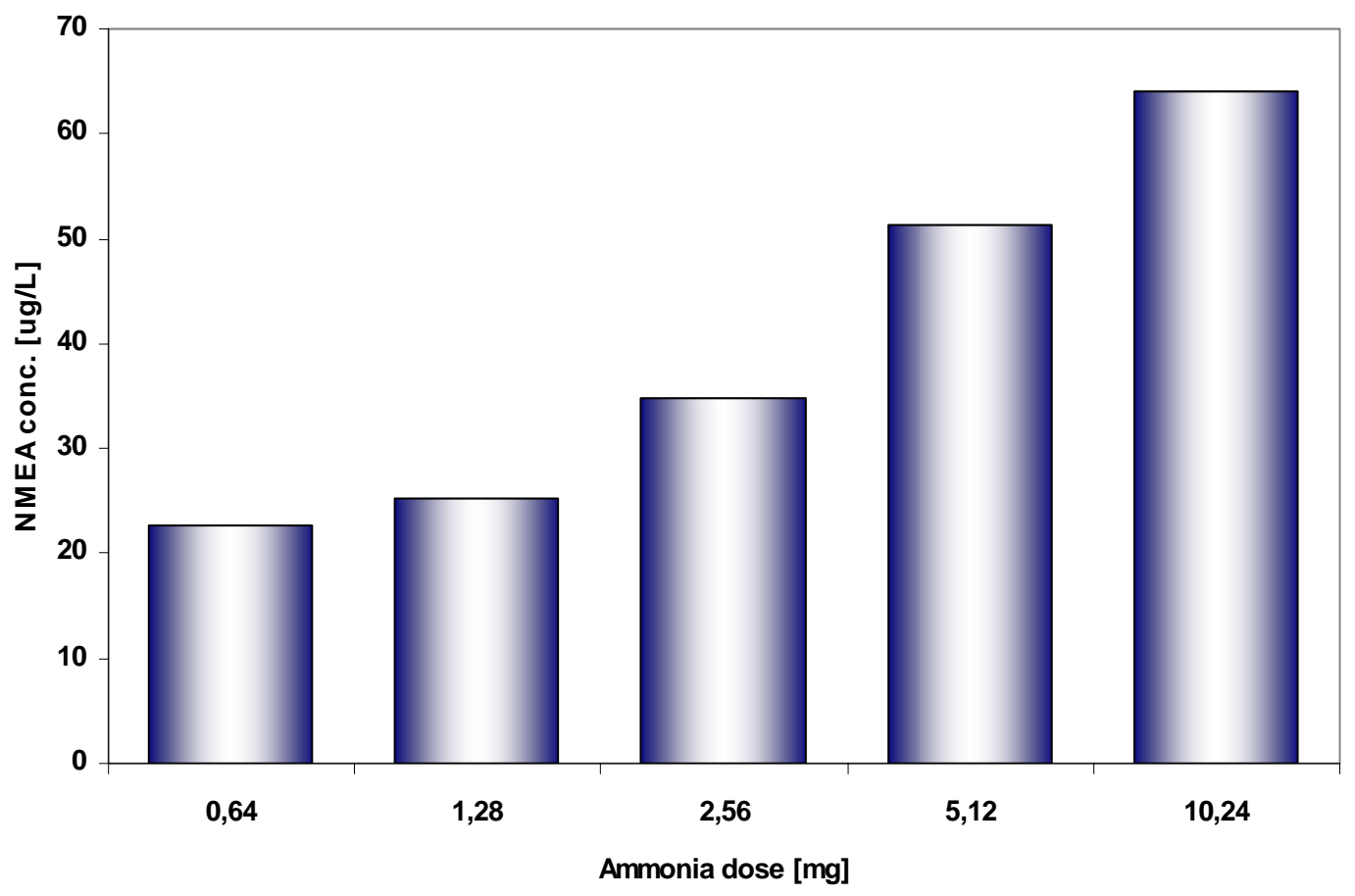

Figure 4. NMEA formation vs. ammonia concentration after 2 hours contact time

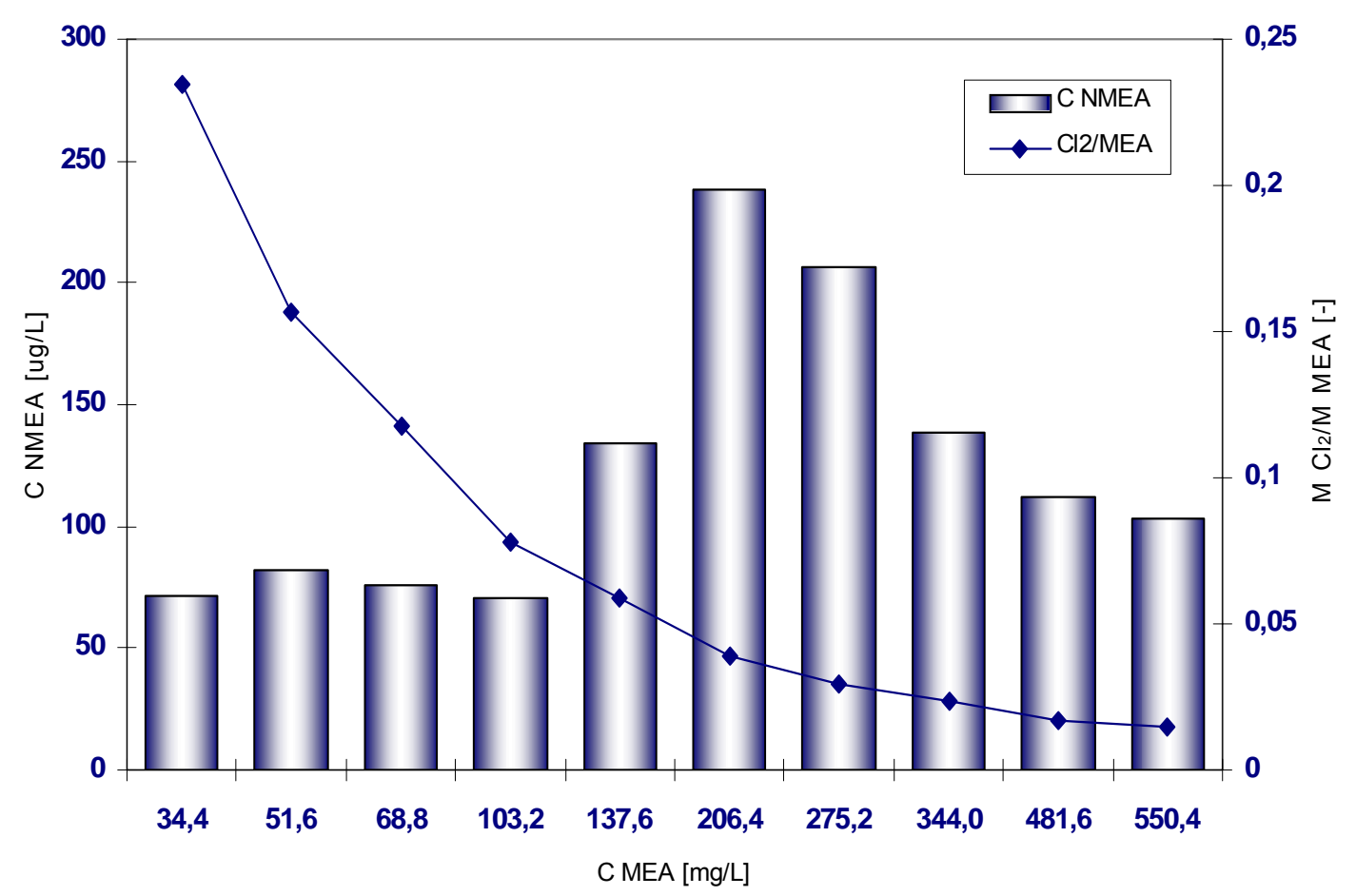

Figure 5. NMEA formation vs. methylethylamine/chlorine molar ratio after 2 hours contact time. 


\subsubsection{The other identified products}

TIC chromatograms of the extracts of post-reaction mixture collected after 6 hours contact time are presented in Figure 6.

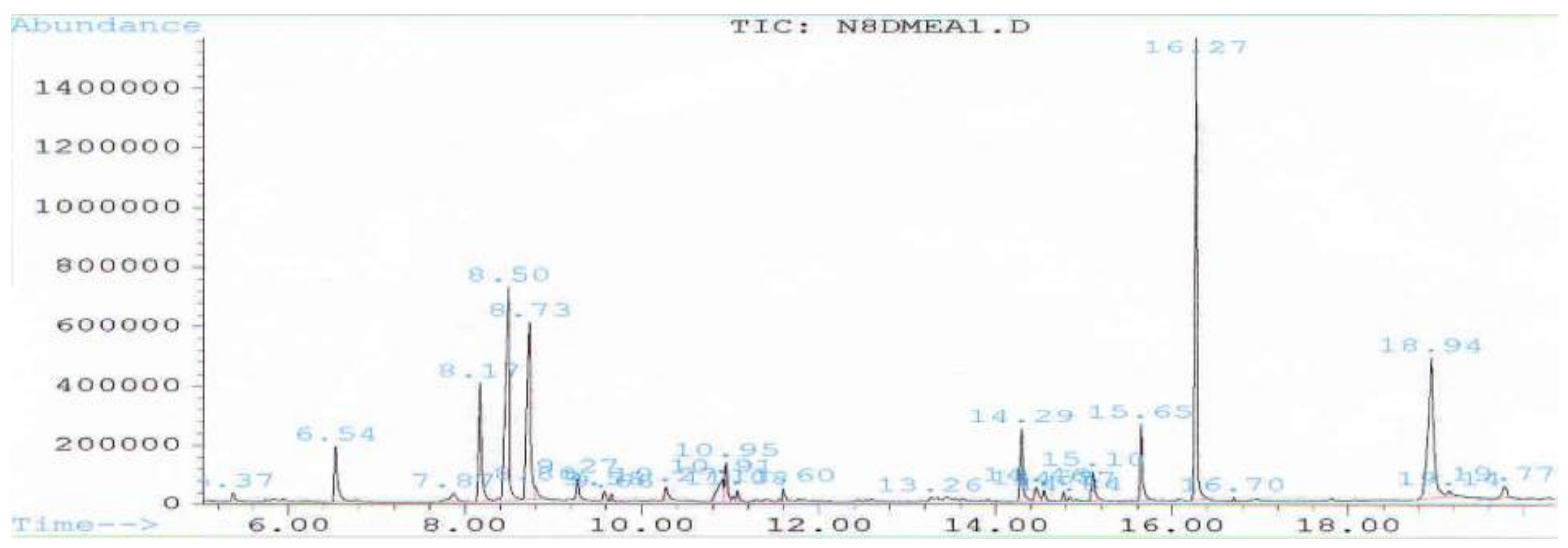

Figure 6. TIC chromatogram of the extracts of after-reaction solution collected after 6 hours contact time.

As can be observed from Fig. 6, NMEA (retention time, $7.88 \mathrm{~min}$ ) is only one of many other products of the reaction and it represents a small part of the total mass of the products formed. Until now, two other products have been identified: ethyl(methyl)formamide (RT=8.73 min on Fig. 6) and 3-ethyl(methyl)aminopropanenitrile ( $R T=10.95$ min on Fig. 6). The first of them is an analogue of DMF (dimethylformamide), which, as reported by Mitch et al. [6] is formed as a result of the reaction of dimethylamine with chlorine in the presence of ammonia ions.

\subsection{N-nitrosodiethylamine formation}

\subsubsection{NDEA formation}

The Figure 7 represents a TIC chromatogram and mass spectrum of the peak of a compound with a retention time of $9.31 \mathrm{~min}$, which was identified in an after-reaction solution of chlorine and diethylamine in the presence of ammonia after 2 hours contact time.

Mass spectrum of a compound with a retention time of $9.31 \mathrm{~min}$ is compatible with mass spectrum of NDEA taken from mass spectra library.

Similarly to the manner of NMEA formation, the results clearly indicate that NDEA is formed as a result of chlorine reaction with diethylamine in the presence of ammonia ions. It is therefore suggested that the reaction follows the scheme proposed by Mitch et al. [6] and Choi et al.[5], although the intermediate product is not UDMH but 1,1diethylhydrazyne.

3.2.2. Influence of relative ratio of substrates on the formation of n-nitrosodiethylamine. The influence of the concentration of ammonia ions and diethylamine on the formation of NDEA was also studied. The results of the influence of the concentration of diethylamine on the formation of NDEA are presented in Figure 8. 


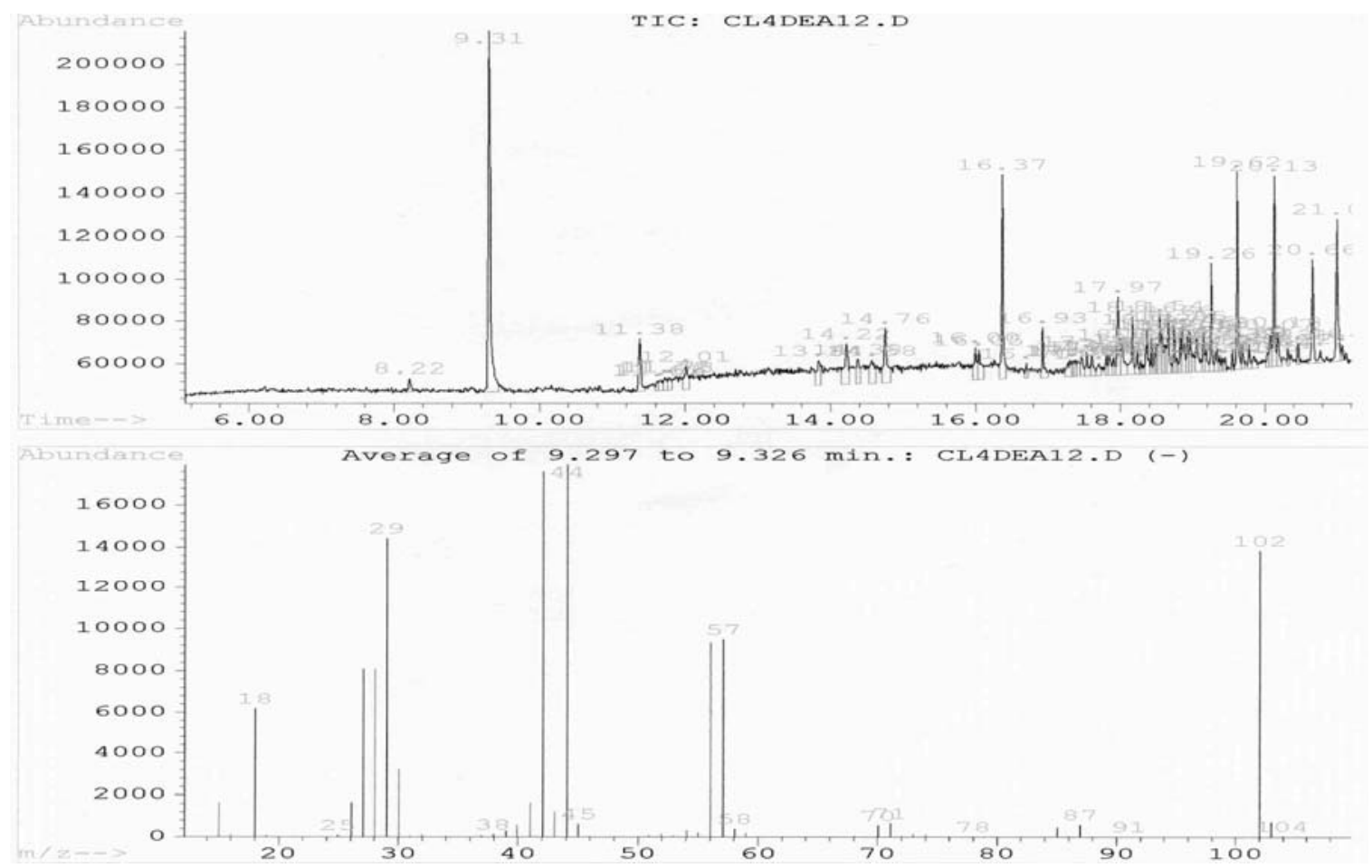

Figure 7. TIC chromatogram and mass spectrum of peak with a retention time of $9.31 \mathrm{~min}$

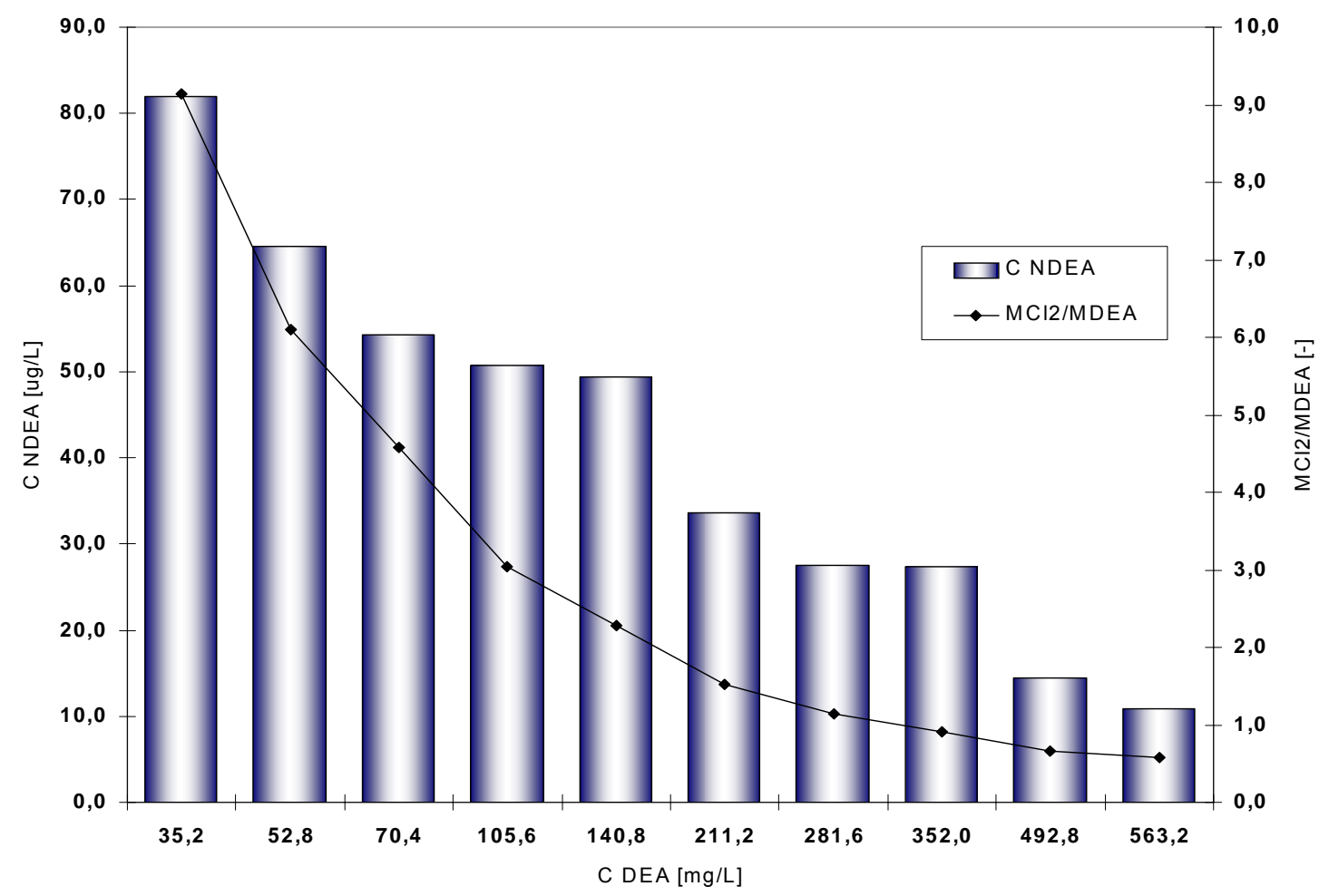

Figure 8. NDEA formation vs. diethylamine/chlorine molar ratio after 2 hours contact time

The results indicated that the changes in the relative ratio of the substrates influence the concentration of NDEA. An increase of concentration of ammonia ions resulted in an increase of the concentration of NDEA. Contrary to NMEA formation, an increase of diethylamine concentration under the conditions of constant concentration of chlorine and 
ammonia resulted only in a decrease of NDEA concentration. The above indicates that the higher chlorine/diethylamine molar ratio leads to the higher potential of NDEA formation.

The maximum DEA/NDEA conversion rate value, calculated as the concentration of DEA to the concentration of NDEA formed quotient, is relatively low and equals $0.16 \%$ [M/M]. This means that the presence of DEA in water at a concentration of only $1 \mu \mathrm{g} \mathrm{I}^{-1}$ can lead to the formation of $2,33 \mathrm{ng} \mathrm{l}^{-1}$ of NDEA. The maximum admissible concentration of NDEA in water according to USEPA regulations [1], is $2 \mathrm{ng} \mathrm{I}^{-1}$.

\section{CONCLUSIONS}

1. N-nitrosomethylethylamine and $\mathrm{N}$-nitrosodiethylamine, the two new potential disinfection by-products, are formed as a result of the reaction of methylethylamine or diethylamine respectively, with chlorine in the presence of ammonia ions.

2. The potential of $\mathrm{N}$-nitrosomethylethylamine and $\mathrm{N}$-nitrosodiethylamine formation is influenced by the concentration of ammonia ions and the relative molar ratio of chlorine and methylethylamine or diethylamine respectively.

3. Ethyl(methyl)formamide and 3-ethyl(methyl)aminopropanenitrile are the other two identified products of the reaction of methylethylamine with chlorine in the presence of ammonia ions.

\section{ACKNOWLEDGMENTS}

Special thanks to Prof. Dr hab. Henryk Jelen from Agriculture University of Poznań for help with the identification of NMEA, NDEA and other products by means of GC-MS analysis.

\section{REFERENCES}

1. www.epa.gov/iris/subst/index.html (10.09.2005)

2. Wunsch, K-H. Miethchen R., Ehlers D. (1979), Organische Chemie Grundkurs, PWN, Warsaw.

3. Gunnison D., Zappi M.E., Teeter C., Pennington J.C., Bajpai R. (2000), Attenuation mechanisms of $\mathrm{N}$-nitrosodimethylamine at an operating intercept and treat groundwater remediation system; Journal of Hazardous Materials, B73, 179-197.

4. Mitch W.A., Sedlak D.L. (2003), A N-nitrosodimethylamine (NDMA) precursor analysis for chlorination of water and wastewater, Water Research, 37, 3733-3741.

5. Choi J., Valentine R.L. (2002), Formation of N-nitrosodimethylamine (NDMA) from reaction of monochloroamine: a new disinfection by-product, Water Research, 36, 817-824.

6. Mitch W.A., Sedlak D.L., (2002), Formation of N-nitrosodimethylamine (NDMA) from dimethylamine during chlorination, Environmental Science and Technology, 36, 588-595.

7. Andrzejewski P., Czerwińska M., Kasprzyk-Hordern B., Nawrocki J. (2004), Analysis and formation of NDMA (N-nitrosodimetyloamine) - the new chlorination byproduct, In: Proceedings of XVIII ${ }^{\text {th }}$ National, $\mathrm{VI}^{\text {th }}$ International Scientific And Technical Conference "Water Supply And Water Quality" Poznań, September 6-8, 2004

8. Andrzejewski P., Kasprzyk-Hordern B. (2005), Secondary nitrosamines - new disinfection byproducts, In: Proceedings of $11^{\text {th }}$ International Scientific And Technical Conference "Soil And Ground Water Contamination By Oil Products And Other Anthropogenic, Organic Compounds: Analytics, Monitoring And Remediation", Ustronie Morski, May 18-21, 2005

9. www.chemfinder.com (10.09.2005) 